\title{
EVALUATION TESTS OF INDUSTRIAL VACUUM BEARINGS FOR SPACE USE
}

\author{
S. Obara ${ }^{[i]}$, A. Sasaki ${ }^{[i]}$, M. Haraguchi ${ }^{[i]}{ }^{*}$, K. Imagawa $^{[i]}$, M. Nishimura ${ }^{[i i]}$ \& N. Kawashima ${ }^{[i i i]}$ \\ [i] National Space Development Agency, 2-1-1 Sengen, Tsukuba, Ibaraki, JAPAN. \\ [ii] Hosei University, 3-7-2 Kajinocho, Koganei, Tokoyo, JAPAN. \\ [iii] Toshiba Corporation, 1 Komukaitoshibacho, Saiwai-ku, Kawasaki, Kanagawa, JAPAN. \\ Telephone: +81-298-52-2402, Fax: +81-298-2410, E-mail: obara.shingo@nasda.go.jp
}

\begin{abstract}
Tribological performance of industrial vacuum bearings was experimentally evaluated for space use. The bearings selected for investigation were an $8 \mathrm{~mm}$ bore-sized deep-groove ball bearing lubricated with a sputtered $\mathrm{MoS}_{2}$ film and that lubricated with an ion-plated $\mathrm{Ag}$ film, commercially delivered from three Japanese domestic bearing-manufacturers. Based on survey results of tribological requirements for the existing satellite mechanisms, four types of bearing tests were defined and conducted: a vacuum test at room temperature, an atmosphere-resistant test, a thermal vacuum test and a vibration test. In addition to these tests, variation in tribological performance of the industrial bearings was also investigated. The results of more than eighty tests demonstrated that the industrial vacuum bearings had sufficient lubrication lives with low frictional torque and their data were reasonably repeatable, indicating very good potentiality for space use.
\end{abstract}

Keywords: Ball bearings, Solid lubricant, Vacuum.

\section{INTRODUCTION}

Within the last decade, the market of solid-lubricated ball bearings for vacuum use has been steadily extended by the requirements mainly from the semi-conductor industry [1]. At present, long-lived, dust-free vacuum bearings for general vacuum-use are commercially available at low cost. If these commercial bearings are applicable to space use, a contribution to reducing the development term and cost of space mechanisms is expected. In view of this expectation, feasibility of the solid-lubricated, commercial vacuum bearings for space use was experimentally evaluated.

Spacecraft mechanisms experience various severe environments, such as operation in humid-air during assembly or testing on the ground, vibration during launch, and operation in vacuum at a wide range of temperature in orbit. In order to evaluate the performance of the commercial bearings for these environments, following four types of test were conducted: (i) a basic life test in vacuum at room temperature with different loads (maximum Hertzian stress at a ball/race interface was in the range of approximately 1 to $2 \mathrm{GPa}$ ), (ii) an atmosphere-resistant test in which the bearings consecutively operated in humid-air for a certain period and then in a vacuum, (iii) a thermal vacuum test at temperature of $-50^{\circ} \mathrm{C}$ to $+60^{\circ} \mathrm{C}$ and (iv) a vibration test.

* Currently, Japan Nuclear Cycle Development Institute.
Another most significant characteristic required for space parts is stability of their quality. From the tribological point of view, quality control of coatings and retainers is crucial to the successful use of the bearings. The coatings and retainers are manufactured in batch process. In this investigation, the variation in tribological response is discussed not only in each batch but among different batches.

These evaluation tests have been accomplished over three years using totally about one hundred seventy bearings commercially available. This paper summarizes these test results. Following companies, a laboratory and society were participated in this activity: NTN Corporation, Koyo Seiko Co., Ltd., NSK Ltd., IHI Heavy Industries Co., Ltd., Kawasaki Heavy Industries, Ltd., NISSAN Aerospace Engineering Co., Ltd., NEC Corporation, Hitachi, Ltd., FUJITSU, Ltd., Mitsubishi Heavy Industries, Ltd., Mitsubishi Electric Corporation, National Aerospace Laboratory and The Society of Japanese Aerospace Companies.

\section{PERFORMANCE-REQUIREMENTS ON BALL BEARINGS FOR SPACE USE}

In order to determine appropriate test conditions of the commercial bearings, performance-requirements on solid-lubricated and oil-lubricated ball bearings applied to the existing spacecrafts were surveyed [2]. Typical requirements and features of the solid-lubricated ball bearings for space use are summarized as follows:

1) Around $10 \mathrm{~mm}$ bore-sized ball bearings have been most frequently used in space applications.

2) Typical life requirement is in the order of $10^{7}$ rotations or less in vacuum, and $10^{4}$ rotations or less in air.

3) Normal operating speed is under $10^{4} \mathrm{DN}$ value, where $\mathrm{DN}$ is defined as the rotational speed of a shaft in rpm multiplied by the bore diameter in $\mathrm{mm}$.

4) Typical qualification temperature requirements are in the range of $-30^{\circ} \mathrm{C}$ to $+80^{\circ} \mathrm{C}$.

5) Applied load is generally less than $10 \%$ of the basic static load rating (BSLR).

6) Component testing of bearings is carried out generally by applying a flexible preload between a pair of the test bearings and measuring their frictional torque. A criterion of $\mu>0.05$, where $\mu$ is a coefficient of friction $(\mathrm{COF})^{* *}$ of a ball bearing, is frequently used for determining the bearing life.

** COF is defined as $\mu=2 T(D F)$, where $T$ is frictional 
torque generated from a single bearing, $D$ is a bore diameter and $F$ is an applied load.

Test bearings and test conditions were determined by referring to these survey results.

\section{TEST BEARINGS}

Two kinds of solid-lubricated ball bearings commercially available from three Japanese bearing-manufacturers were selected as the test bearings (hereafter, the bearing fabricated by each bearing-manufacturer is denoted by bearings $\mathrm{A}, \mathrm{B}$ and $\mathrm{C}$ ). The types and materials of the test bearings are listed in Table 1. A sputtered $\mathrm{MoS}_{2}$ film and a PTFE based composite retainer is a popular combination in commercial vacuum bearings as well as space applications. An ion-plated Ag film is also frequently applied to the semi-conductor manufacturing process because of its very low outgassing characteristic in vacuum.

Table 1. Test Bearings

\begin{tabular}{|l|l|l|}
\hline \multicolumn{2}{|l|}{ Bearing type } & $\begin{array}{l}8 \mathrm{~mm} \text { bore-sized deep groove ball } \\
\text { bearing (No. 608 type) }\end{array}$ \\
\hline $\begin{array}{l}\text { Material of balls and } \\
\text { races }\end{array}$ & 440C stainless steel \\
\hline \multirow{2}{*}{$\begin{array}{l}\text { Lubri- } \\
\text { cants }\end{array}$} & $\begin{array}{l}\text { Pre-coated } \\
\text { film }\end{array}$ & $\begin{array}{l}\text { Sputtered } \mathrm{MoS}_{2} \text { film } \\
\text { (balls and races), } \\
\text { Ion-plated Ag film (balls only) }\end{array}$ \\
\cline { 2 - 3 } & Retainer & PTFE based composite \\
\hline Storage & $\begin{array}{l}\text { Vacuum pack, or Sealed bags } \\
\text { purged with dry inert gas }\end{array}$ \\
\hline
\end{tabular}

1) A $12 \mathrm{~mm}$ bore-sized deep groove ball bearing (No. 6001 type) was also used in few cases.

\section{TESTING}

\subsection{Test Conditions}

Since bearings in the space mechanisms experience different severe environments on the ground, during launch and in orbit, their feasibility should be evaluated from many aspects. Following four types of bearing tests were defined in this investigation.

(1) Room-Temperature Vacuum Test

This is a simple life test of the bearings conducted in vacuum at room temperature $\left(\mathrm{RT}, 20 \sim 30^{\circ} \mathrm{C}\right.$ ). The test conditions are listed in Table 2. Axial loads were selected in the range of approximately $1 \%$ to $15 \%$ of BSLR of a No. 608 type bearing.

Table 2. Conditions of Room-Temperature Vacuum Test

\begin{tabular}{|l|l|}
\hline Axial load & $\begin{array}{l}20 \mathrm{~N}, 100 \mathrm{~N}, 200 \mathrm{~N} \\
\text { (Max. Hertzian stress: } 0.8 \sim 1.9 \mathrm{GPa})\end{array}$ \\
\hline Rotational speed & $500 \mathrm{rpm}$ \\
\hline Environment & Vacuum $<10^{-4} \mathrm{~Pa}, \mathrm{RT}$ \\
\hline $\begin{array}{l}\text { Test Completion } \\
\text { Criteria (TCC) }\end{array}$ & $10^{7}$ revs or COF $>0.05$ \\
\hline
\end{tabular}

(2) Atmosphere-Resistant Test

This test was made to evaluate degradation of a solid lubricant due to in-air operation, where the bearings consecutively operated in humid-air and then in vacuum. The test conditions are listed in Table 3. Selected axial loads were about $8 \%$ or less of BSLR.

Table 3. Conditions of Atmosphere-Resistant Test

\begin{tabular}{|l|l|l|}
\hline \multirow{4}{*}{$\begin{array}{l}\text { In-air } \\
\text { operation }\end{array}$} & Rotational speed & $500 \mathrm{rpm}$ \\
\cline { 2 - 3 } & Axial load & $\begin{array}{l}10 \mathrm{~N}, 20 \mathrm{~N}, 100 \mathrm{~N}(\mathrm{Max} . \\
\text { Hertzian stress: } 0.6 \sim 1.6 \mathrm{GPa})\end{array}$ \\
\cline { 2 - 3 } & Environment & Air, Humidity $<60 \% \mathrm{RH}, \mathrm{RT}$ \\
\cline { 2 - 3 } & TCC & $5 \times 10^{4}$ revs or COF $>0.05$ \\
\hline \multirow{3}{*}{$\begin{array}{l}\text { In-vacuo } \\
\text { operation }\end{array}$} & Rotational speed & $500 \mathrm{rpm}$ \\
\cline { 2 - 3 } & Axial load & $10 \mathrm{~N}, 20 \mathrm{~N}, 100 \mathrm{~N}$ \\
\cline { 2 - 3 } & Environment & Vacuum $<10^{-4} \mathrm{~Pa}, \mathrm{RT}$ \\
\cline { 2 - 3 } & TCC & $10^{7}$ revs or COF $>0.05$ \\
\hline
\end{tabular}

(3) Thermal Vacuum Test

The temperature of a bearing test apparatus was controlled in the range from $-50^{\circ} \mathrm{C}$ to $+60^{\circ} \mathrm{C}$. This temperature range was selected considering the operating capabilities of the bearing test apparatus and test facility. The operation of the test bearings was continued throughout the test. Table 4 presents the test conditions.

Table 4. Conditions of Thermal Vacuum Test

\begin{tabular}{|l|l|}
\hline Rotational speed & $500 \mathrm{rpm}$ \\
\hline Axial load & $10 \mathrm{~N}$ \\
\hline Environment & Vacuum $<10^{-4} \mathrm{~Pa}$ \\
\hline Temperature & $\begin{array}{l}2 \text { cycles of operation at }-50^{\circ} \mathrm{C} \text { for } 72 \\
\text { hours and }+60^{\circ} \mathrm{C} \text { for } 72 \text { hours }\end{array}$ \\
\hline TCC & $10^{7}$ revs or COF $>0.05$ \\
\hline
\end{tabular}

(4) Vibration Test

First, a pair of test bearings was assembled in a bearing housing with a shaft. This assembly experienced sinusoidal and random vibrations in air, and then was operated in vacuum. The test conditions are summarized in Table 5. A dynamic load exerted to the test bearing during sinusoidal vibration in the axial direction was estimated to be approximately $50 \%$ to $60 \%$ of the maximum permissible axial load of the test bearing.

Table 5. Conditions of Vibration Test

\begin{tabular}{|c|c|c|}
\hline \multirow{4}{*}{$\begin{array}{l}\text { Applying } \\
\text { vibration }\end{array}$} & Environment & Air, Humidity $<60 \%$ RH, RT \\
\hline & $\begin{array}{l}\text { Sinusoidal } \\
\text { vibration }\end{array}$ & $\begin{array}{l}\text { Frequency: } 5 \sim 200 \mathrm{~Hz} \text {. } \\
\text { Target maximum acceleration } \\
\text { of the main-shaft: } 25 \mathrm{G}\end{array}$ \\
\hline & Random vibration & $\begin{array}{l}\text { Frequency: } 20 \sim 2000 \mathrm{~Hz} . \\
\text { Duration time: } 3 \mathrm{~min} . \\
\text { Target maximum acceleration } \\
\text { of the main-shaft: } 25 \mathrm{Grms}\end{array}$ \\
\hline & $\begin{array}{l}\text { Vibrating } \\
\text { directions }\end{array}$ & $\begin{array}{l}\text { Three mutually perpendicular } \\
\text { directions (one axial direction } \\
\text { and two radial directions) }\end{array}$ \\
\hline \multirow{4}{*}{$\begin{array}{l}\text { In-vacuo } \\
\text { operation }\end{array}$} & Rotational speed & $500 \mathrm{rpm}$ \\
\hline & Axial load & $10 \mathrm{~N}$ \\
\hline & Environment & Vacuum $<10^{-4} \mathrm{~Pa}, \mathrm{RT}$ \\
\hline & TCC & $10^{7}$ revs or $\mathrm{COF}>0.05$ \\
\hline
\end{tabular}


The room-temperature vacuum tests and some of the atmosphere-resistant tests were conducted at the laboratories of the three bearing-manufacturers participated in this study. Other tests were implemented with the High Vacuum Test Facilities for Mechanical Components [3] at Tsukuba Space Center of NASDA.

In the four types of test mentioned above, frictional torque was measured throughout the tests. During invacuo operation, residual gas was analyzed periodically using a quadruple mass analyzer. After the test, wear of balls and raceways were estimated from their roundness or surface profiles.

\subsection{Number of Tests}

Each combination of pre-coated films $\left(\mathrm{MoS}_{2}\right.$ and $\left.\mathrm{Ag}\right)$ and manufacturers (A, B and C) was tested once in all the tests, except for the room-temperature vacuum test in which the test was repeated one or two times.

In addition to these tests, variability in the lubricating quality of the commercial bearings was evaluated by the atmosphere-resistant test at an axial load of $100 \mathrm{~N}$ using additional $\mathrm{MoS}_{2}$-lubricated bearings. These bearings were produced in two different batches, where one batch production was made at about one year's interval after the production of the first tested bearings, and then the other batch production was made at one month's interval. Since the first tested bearings had been also made in a single batch, by including this result, variation among three batches over one year and one month could be estimated. (Hereafter, in the order of production date, each batch is referred as batches I, II and III. Batch II was made at one year's interval after batch I, and batch III one month's interval after batch II.) For evaluating variation within a single batch, each combination of batches and manufacturers was tested six times for batch II and three times for batch III.

\section{TEST APPARATUS}

Bearing test apparatuses used were classified into two types. One was a conventionally used flexibly-preloaded two-bearing tester in which rotatory motion was applied to the inner races and their resultant frictional torque was estimated by measuring force required to hold the outer races stationary. The three bearing manufacturers used this type of apparatus.

The other type was originally designed in NASDA to be applicable to both the thermal vacuum test and the vibration test. Figure 1 shows a schematic diagram of the bearing test apparatus. A pair of the test bearings was attached to a 440C stainless-steel shaft (main-shaft). An axial load was imposed using a coil spring placed at the end of the main-shaft. These components were assembled in a bearing holder made of aluminum alloy (Test Housing Assembly, THA). In order to couple with a support-shaft, a disc with two offset horizontal bars was secured to the end of the main-shaft.

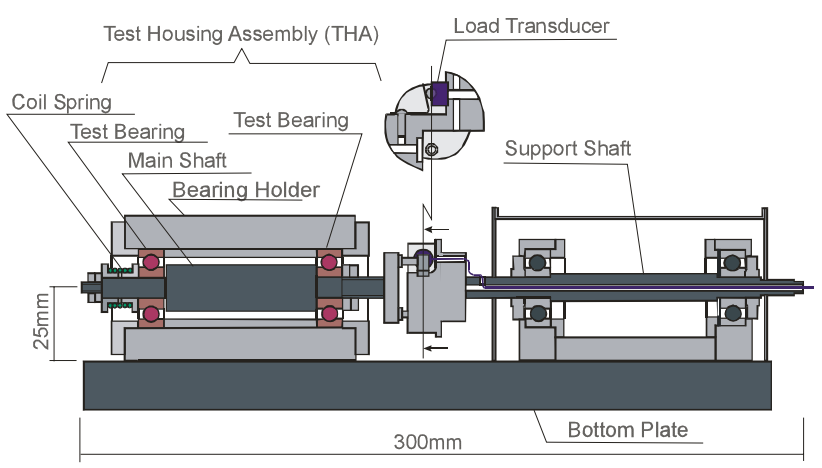

Figure 1 Bearing test apparatus at NASDA

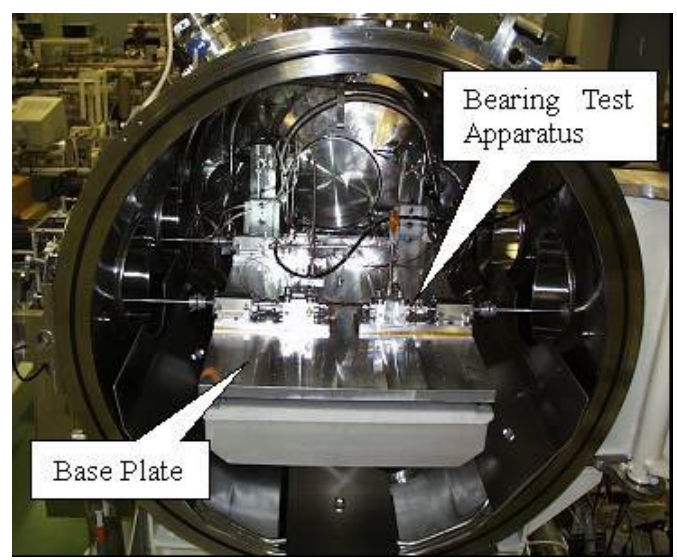

Figure 2. Thermal vacuum test configuration

The support-shaft was axially aligned with the mainshaft, and supported with two PFPE-grease-lubricated ball bearings. A load transducer was offset from a center of rotation and bonded on the end of the support-shaft. Rotatory motion of the support-shaft applied from the outside of the vacuum chamber was transmitted to the main-shaft through the load transducer (namely, the load transducer pushes one of the offset horizontal bars in the circumferential direction). Since the support-shaft rotates at a constant speed, load-variation sensed with the load transducer during its rotation shows the frictional torque generated from the two test bearings. Output from the load transducer was transferred to the outside of the vacuum chamber through first the inside bore of the support-shaft, then a feed-through mounted in the inside bore and then a slip-ring located at the outside of the chamber. Figure 2 shows a photograph of the thermal vacuum test configuration, where three bearing test apparatuses were fastened on a thermally-controllable base-plate in the vacuum chamber.

For the case of the vibration test, THA was removed from a bottom plate in Fig. 1, and only THA was vibrated with a shaker. When a large dynamic load during vibration was required, an extra mass of $1.5 \mathrm{~kg}$ was attached to the main-shaft of THA. Figure 3 shows a photograph of the vibration test configuration when vibrating in the axial direction. In Fig. 3, THA is fastened 
in a vibration jig, and the extra mass is seen at the middle of THA (Though the extra mass looks attached to the bearing housing of THA, it was fixed to the main-shaft and did not make contact with the bearing housing).

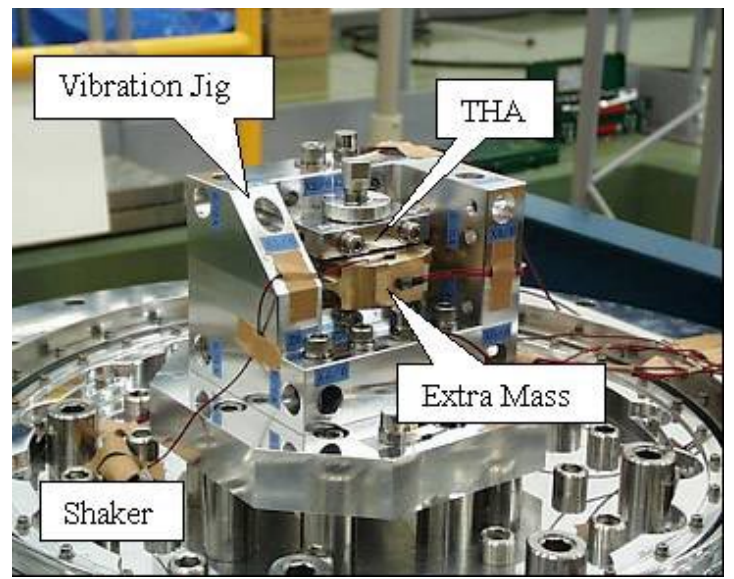

Figure 3. Vibration test configuration

\section{RESULTS}

\subsection{Room-Temperature Vacuum Test}

COFs of the $\mathrm{MoS}_{2}$ lubricated and Ag lubricated bearings in vacuum are shown in Figs. 4 and 5, respectively. In this test, No. 6001 type bearings were used as bearing C. Their axial loads were selected so that the maximum Hertzian stress between a ball and race was equivalent to those of No. 608 type bearings of bearings A and B. In Fig. 4, all the $\mathrm{MoS}_{2}$ lubricated bearings successfully operated to $10^{7}$ rotations in vacuum with stable COFs of less than 0.02. Similar results between Fig. 4(a) and 4(b) suggest that $\mathrm{COF}$ was not dependent on the axial load.

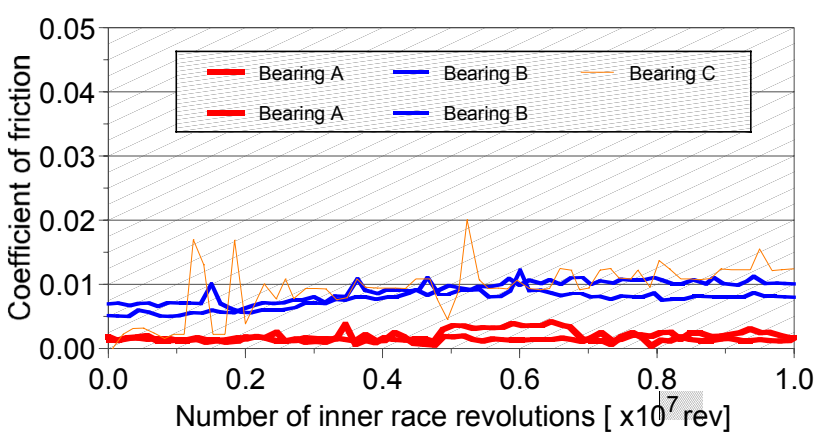

(a) At axial load of $20 \mathrm{~N}$

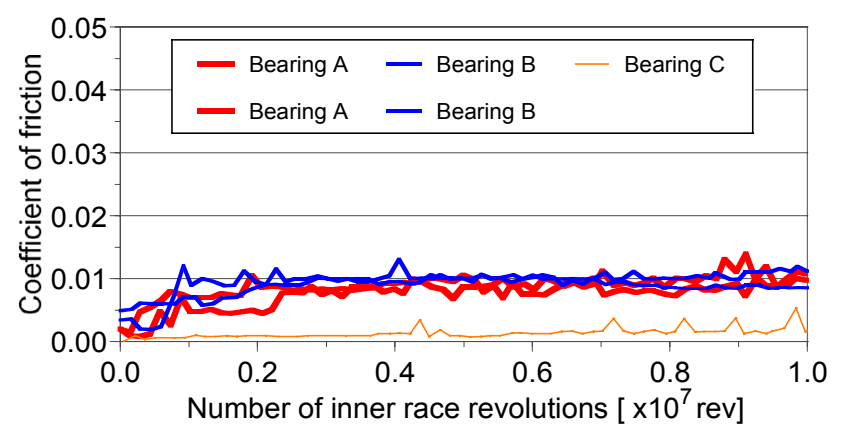

(b) At axial load of $200 \mathrm{~N}$

Figure 4. COF of $\mathrm{MoS}_{2}$ lubricated bearings in vacuum at Room Temperature.

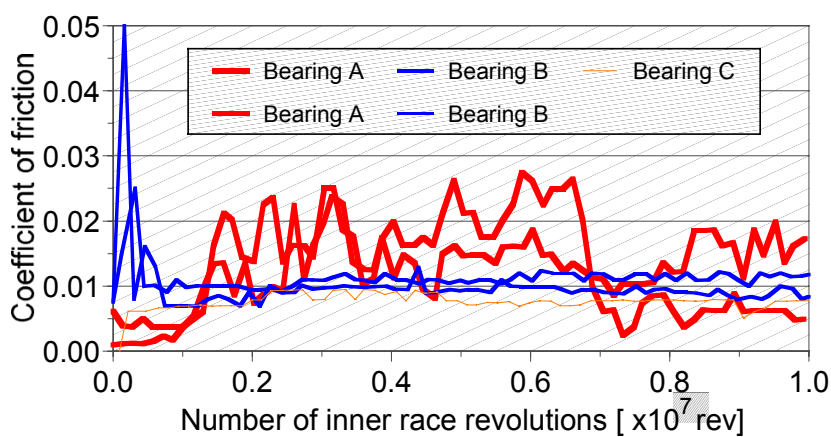

(a) At axial load of $20 \mathrm{~N}$

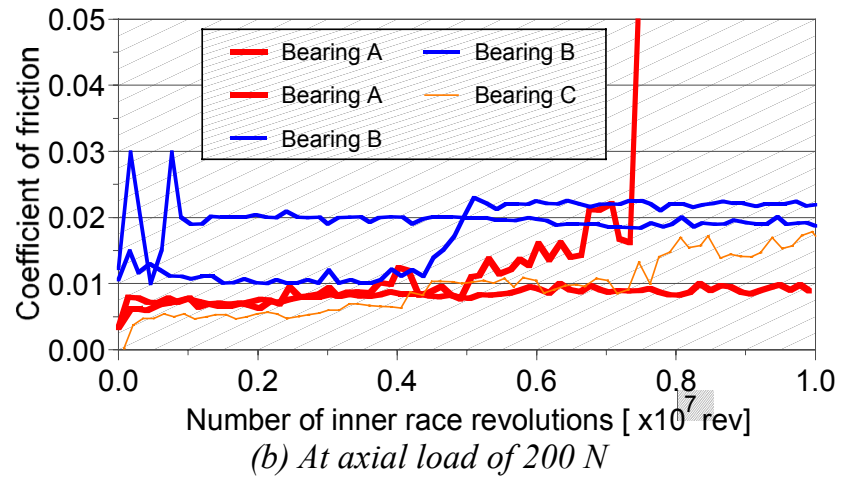

Figure 5. COF of Ag lubricated bearings in vacuum at Room Temperature.

For the case of the Ag lubricated bearings in Fig. 5(a), relatively higher COFs were found for bearings $\mathrm{A}$ and $\mathrm{B}$ compared with bearing C. An EPMA (electron probe microanalysis) investigation of the raceways after the tests revealed that bearings $\mathrm{A}$ and $\mathrm{B}$ formed thicker $\mathrm{Ag}$ films on the raceways than bearing $\mathrm{C}$, and this may be a possible cause of their high COFs. At a large axial load in Fig. 5(b), COFs of most bearings were gradually increased and high values continued throughout the tests. One bearing reached the friction criterion of 0.05 , but its life of about $7 \times 10^{6}$ revolutions at an axial load of $200 \mathrm{~N}$ (max. Hertzian stress: 1.9 GPa) may be acceptable for some space applications.

From Figs. 4 and 5, it is found that COFs of the bearings produced by each manufacturer were repeatable, but relatively large difference in COFs appeared depending on the manufacturers, especially for the case of the Ag lubricated bearings. As for wear of the balls and raceways, a little wear of less than $5 \mu \mathrm{m}$ in depth was observed at the highest axial load of $200 \mathrm{~N}$, and less than $1 \mu \mathrm{m}$ at the other loads.

\subsection{Atmosphere-Resistant Test}

COFs of the $\mathrm{MoS}_{2}$ and Ag bearings operated at an axial load of $10 \mathrm{~N}$ in vacuum are shown in Figs. 6(a) and 6(b), respectively. These in-vacuo operations were made consecutively after in-humid-air operation up to $5 \times 10^{4}$ revolutions. Although relatively high $\mathrm{COF}$ appeared for bearing $\mathrm{B}$, all the bearings completed $10^{7}$ revolutions. Short life had been expected for the $\mathrm{Ag}$ lubricated 
bearings due to oxidation of an Ag film [4], but they successfully completed these tests.

For the other axial loads of $20 \mathrm{~N}$ and $100 \mathrm{~N}$, all the test bearings also accomplished in-air operation and consecutive in-vacuo operation with the almost identical COFs shown in Fig. 6. The selected lubricant combinations of pre-coated films and retainers seem to have reasonable humid-air resistance for practical use.

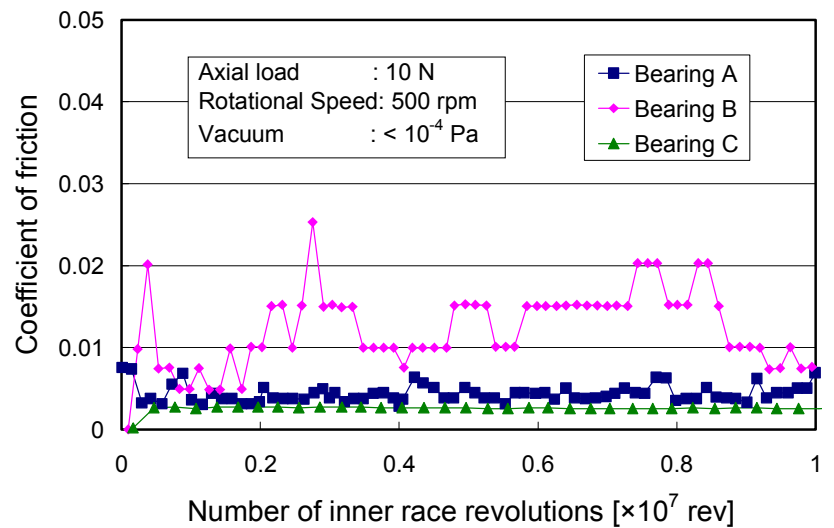

(a) $\mathrm{MoS}_{2}$ lubricated bearing

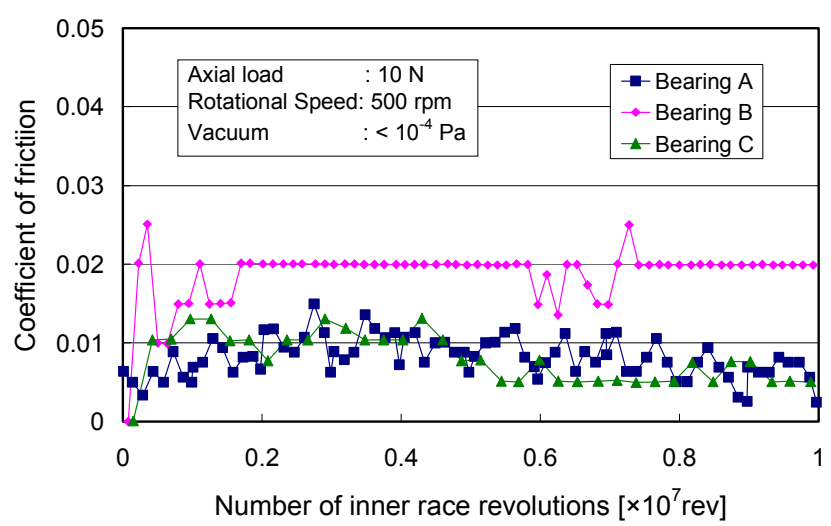

(b) Ag lubricated bearing

Figure 6. COFs of the bearings during in-vacuo operation after in-air operation.

\subsection{Thermal Vacuum Test}

Figure 7 presents COFs of the $\mathrm{MoS}_{2}$ and $\mathrm{Ag}$ lubricated bearings in the thermal vacuum test. Temperature trace at a reference point on the base-plate for its thermal control is also shown in Fig. 7. Temperatures at the outer races of the test bearings were monitored using thermocouples throughout the tests, and their values changed within $\pm 5^{\circ} \mathrm{C}$ of the reference point temperatures. Although slight increases in COFs appeared, the $\mathrm{MoS}_{2}$ lubricated and $\mathrm{Ag}$ lubricated bearings successfully run to $10^{7}$ rotations in thermal vacuum environment.

For the Ag lubricated bearings in Fig. 7(b), the bearings A and B showed relatively high COFs at low temperature. However, these bearings seems to have been successfully lubricated by pre-coated Ag films because uniformly transferred Ag films were detected by EPMA and little wear of less than $1 \mu \mathrm{m}$ in depth was observed on the raceways.

In all the tests shown in Fig. 7, pressure in the vacuum chamber was under $2 \times 10^{-5} \mathrm{~Pa}$. Outgassing from the test bearings did not observed in the residual gas analysis.

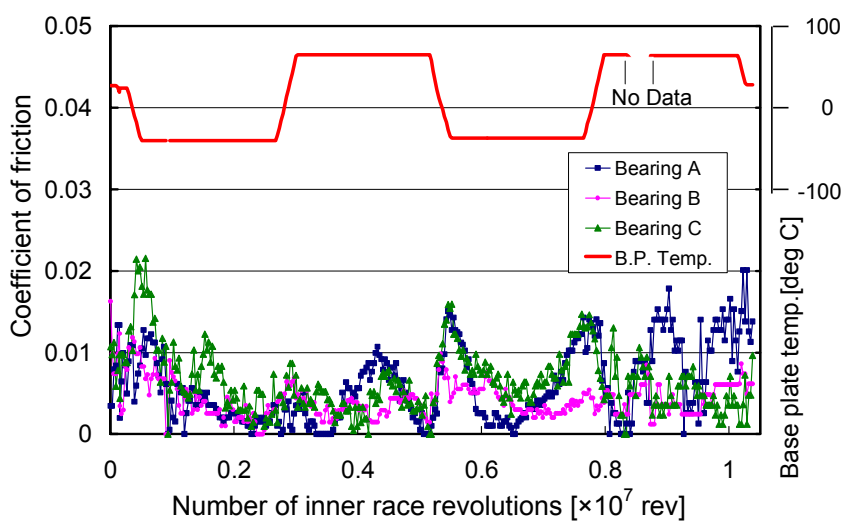

(a) $\mathrm{MoS}_{2}$ lubricated bearing

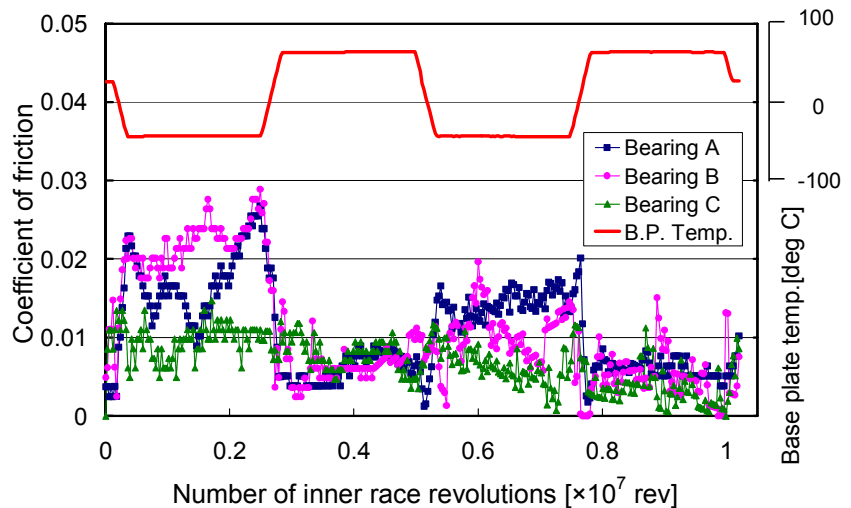

(b) Ag lubricated bearing

Figure 7. COFs of the bearings operated in thermal vacuum environment.

\subsection{Vibration Test}

Figure 8 shows COFs of the $\mathrm{MoS}_{2}$ and Ag lubricated bearings in vacuum after experience of vibration. All the bearings completed $10^{7}$ revolutions with very low and stable COFs. The experience of vibration is considered to have exerted negligible influence upon the normal operation and life of the bearings.

Influence of vibration, however, appeared in other aspects. Figure 9 shows SEM photographs of the ball and inner-raceway surfaces of the Ag pre-coated bearing after vibration. Some scars are found on both surfaces. (For reference, dimension of Hertzian contact ellipse without a lubricant film is about $500 \mu \mathrm{m} \times 35 \mu \mathrm{m}$ under static axial load condition.) From the fact that scar on the raceway is longer than that on the ball surface, occurrence of rolling-sliding motion is expected between balls and raceways during vibration. In all the tests, starting torque of the bearings was measured before and after vibration. 
The starting torque was found to increase approximately 1.5 times or less due to experience of vibration.

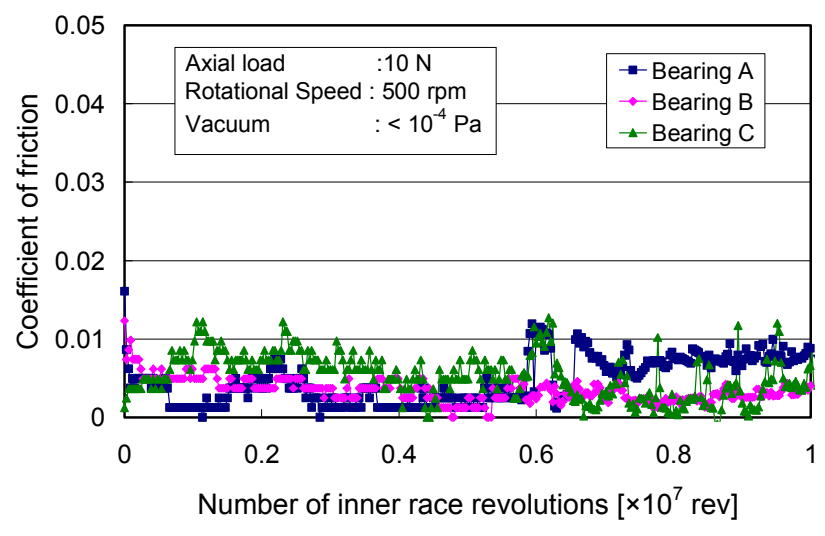

(a) $\mathrm{MoS}_{2}$ lubricated bearing

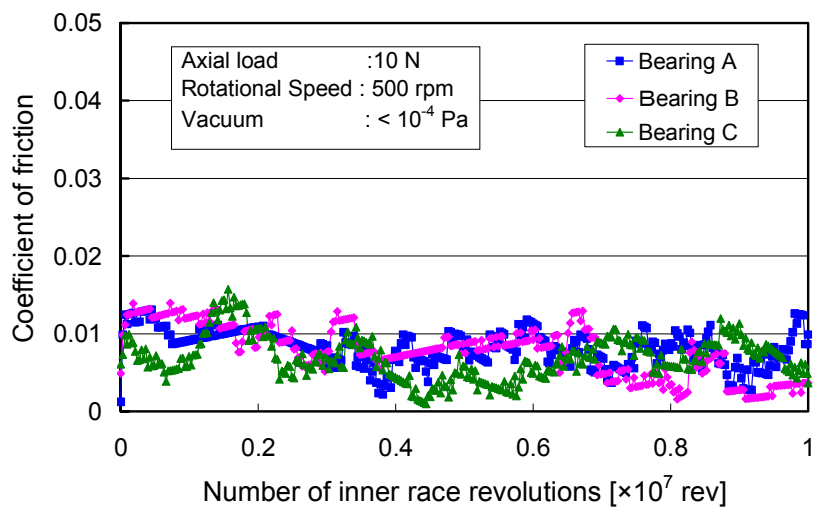

(b) Ag lubricated bearing

Figure 8. COFs of the bearings operated in vacuum after experience of vibration.

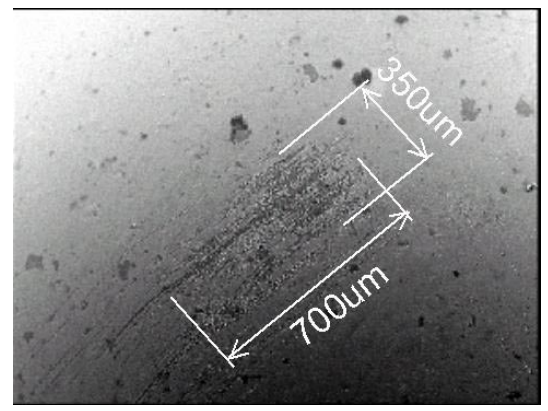

(a) Ball surface

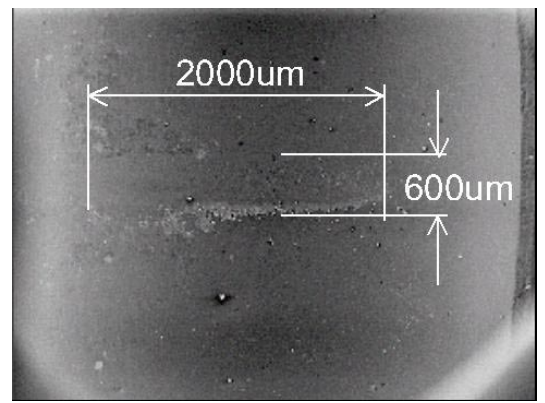

(b) Inner raceway

Figure 9. SEM photographs of the Ag-lubricated bearing after experience of vibration
From these results, the influence of vibration on the test bearings can be summarized as follows: during vibration a pre-coated solid lubricant film was worn due to rolling-sliding motion between a ball and raceway, and resultant scars increased the starting torque of the bearings. However, the generation of scar did not affect the frictional torque in normal operation and lives.

\subsection{Variability in Tribological Performance of Bearings}

Variation in the tribological performance of the commercial bearings was evaluated by the atmosphereresistant tests, where the bearings operated in humid-air and then in vacuum. Before testing, each test bearing was stored in a vacuum pack or in a heat-sealed bag purged with an inert gas. We had preliminarily confirmed that the storage term for at least two years by this manner did not affect the lubrication performance of the bearings.

(1) Variation Within a Single Batch

COFs of six pairs of bearing $\mathrm{C}$ during vacuum operation are shown in Fig. 10. These bearings were produced in batch II, and the tests were conducted in a single laboratory using a defined apparatus. The identical COF traces are found. Figure 11 shows the summary of the change in the COFs of bearings $\mathrm{A}, \mathrm{B}$ and $\mathrm{C}$ in vacuum operation. Three pairs of bearings A1 to A3, and six pairs of B1 to B6 were also individually manufactured in a single batch II. Although noticeable differences in COFs appear depending on the manufacturers, repeatability within each manufacturer is very good. From these results, variation in the lubrication performance of the bearings produced in a single batch was confirmed to be small.

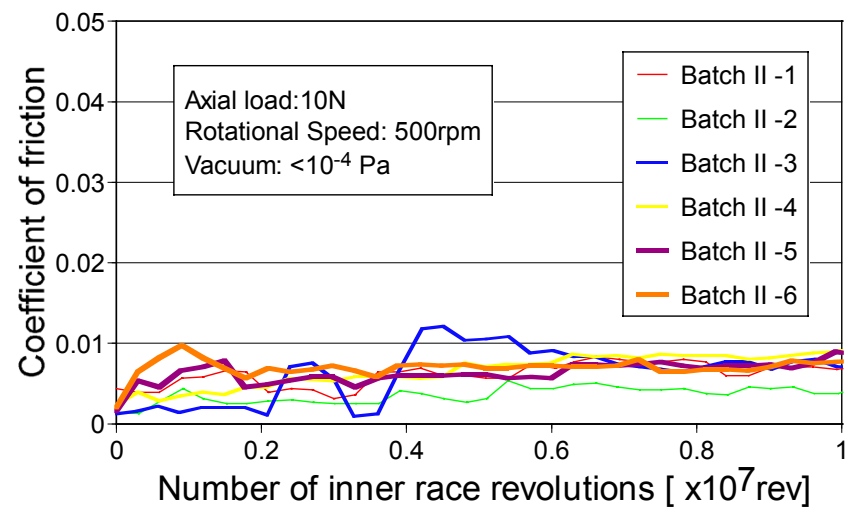

Figure 10. COFs of bearings $C$ manufactured in a single batch. In-air operation had been conducted at 26 to $30 \%$ RH.

As for bearing A in Fig. 11, only three data are presented because the other three tests were performed at high humidity $(63 \% \mathrm{RH}$ or more) in excess of the test-condition requirement (humidity $<60 \% \mathrm{RH}$ ). The three results obtained in the high humidity showed following behavior: COFs during in-air operation were relatively low and stable (less than 0.01 ), but in the 
consecutive in-vacuo operation, they were gradually increased more than 0.03 and became fluctuated. One of the three tests was terminated at $6 \times 10^{6}$ rotations because its $\mathrm{COF}$ exceeded the test completion criterion of 0.05 .

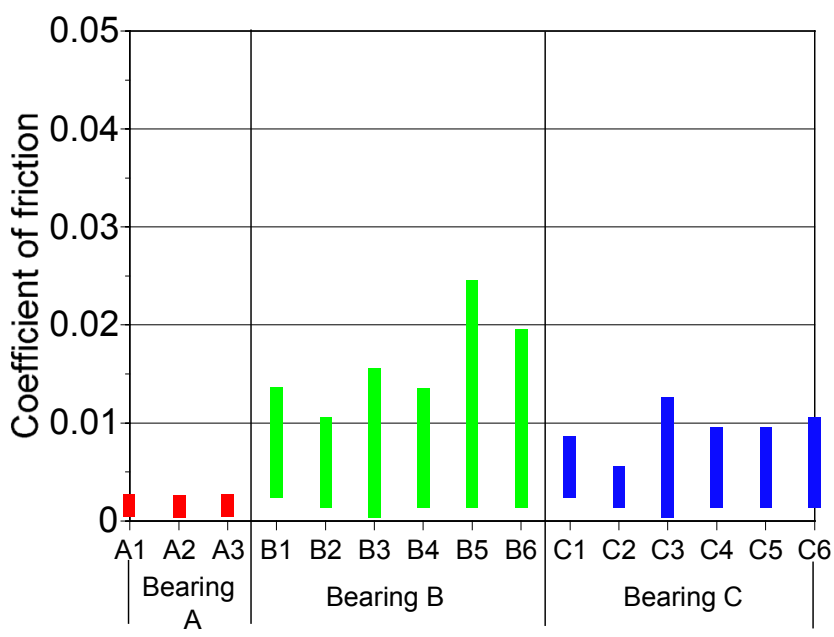

Figure 11. Change in the COF during vacuum operation. In-air operation of the bearings $A, B$ and $C$ had been conducted at around $45 \% \mathrm{RH}, 32$ to $34 \% \mathrm{RH}$ and 26 to $30 \% R H$, respectively.

(2) Variation Between Batches

COFs of the bearings fabricated in three different batches are shown in Fig. 12. Production of batch II was made one year's interval after that of batch I, and batch III one month's interval after batch II. The results in Fig. 12(a) and those in 12(b) were individually obtained in a single laboratory using a defined apparatus. COFs for bearing B in Fig. 12(b) are found to be reasonably repeatable. COFs for bearing $\mathrm{C}$, not presented herein, also shows good repeatability. On the contrary, as for bearing A in Fig. 12(a), COFs between batches I and III were well identical $(\mu=0.01 \sim 0.02)$, but COF of batch II was much smaller $(\mu<0.002)$ than those of batches I and III. It can be summarized that COFs in different batches were satisfactorily low and stable, but batch-to-batch variation was slightly larger than variation within a single batch.

(3) Variation Due to Test Apparatus

We also assessed the repeatability of COFs between different test apparatuses. A comparison of COFs obtained from different apparatuses is presented in Fig. 13, where all the bearings were produced in batch II, and the tests were conducted using NASDA's or bearing-manufacturer C's apparatus under the same test condition. Although the mechanisms of these test apparatuses were different as mentioned in the previous section, the obtained results were reasonably identical. This suggests that repeatable friction data of solid-lubricated ball bearings could be obtained at different laboratories by applying standardized test procedures.

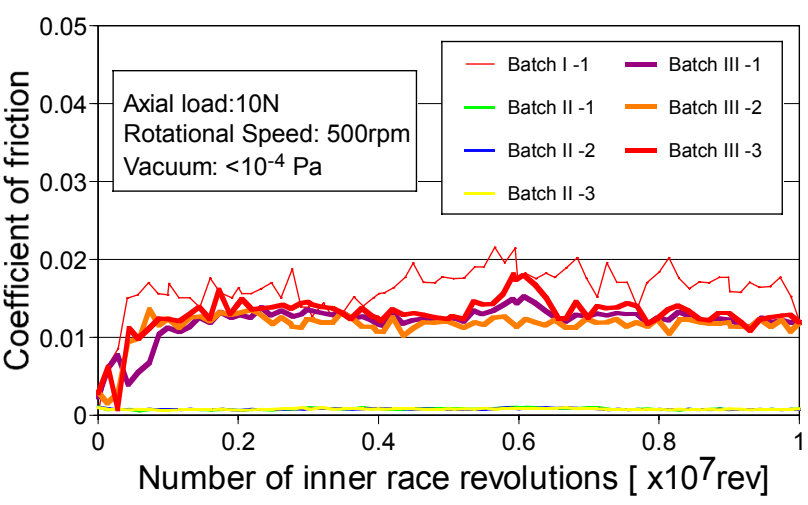

(a) Bearings $A$

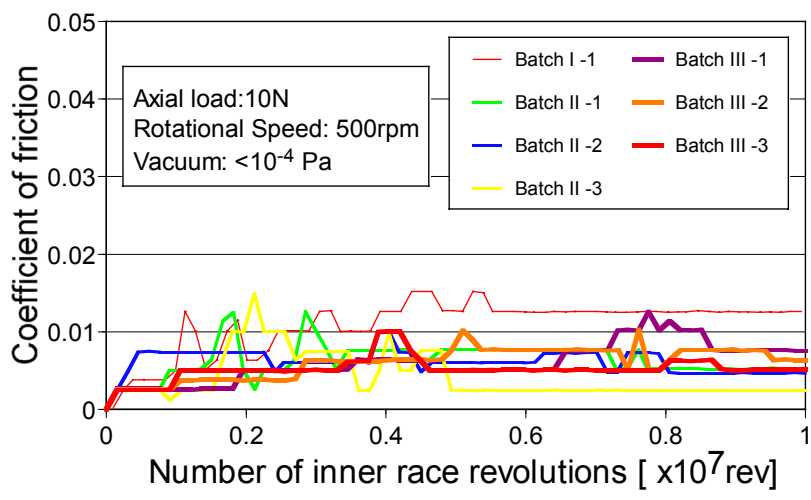

(b) Bearings $B$

Figure 12. COFs of the bearings fabricated in three different batches. In-air operation of the bearings $A$ and $B$ had been conducted at 32 to $45 \%$ RH and 31 to $39 \%$ RH, respectively.

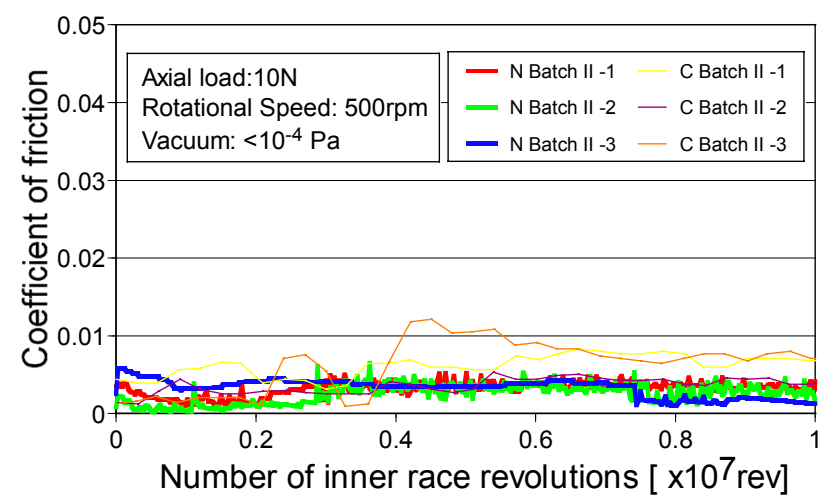

Figure 13. COFs measured with NASDA's apparatus (referred as " $N$ ") and bearing-manufacturer $C$ 's apparatus (" $C$ "). All the test bearings were manufactured in a single batch II. In-air operation had been conducted at 30 to $39 \%$ RH in both the laboratories.

\section{SUMMARY}

In order to evaluate the applicability for space use, solid-lubricated ball bearings manufactured for general vacuum-use were tested in humid-air, thermal vacuum, vibration environment and other conditions. Most bearings showed very good tribological performance with a long life of more than $10^{7}$ rotations and a stable, low friction coefficient of less than 0.05 . 
In addition, tribological response was assessed between the commercial bearings produced in different batches. Variation in friction characteristics in each batch and among different batches was within allowable range, though the latter was slightly larger than the former.

From these successful results, it can be concluded that the industrial vacuum bearings can meet the tribological requirements of many space mechanisms and they have very good potentiality for space use.

\section{ACKNOWLEDGEMENTS}

The authors would like to thank all the participants in this investigation for their valuable contributions.

\section{REFERENCES}

[1] S. Miyake, ASME Jour. of Tribology, Vol. 122, No. 4, 2000, pp. 796-802.

[2] S. Obara, et al. The 42nd Space Sciences and Technology Conference, 1F-11, 1998. (in Japanese).

[3] K. Gotoh, et al., Proc. of 22nd International Symposium on Space Technology and Science, 98-e-22 1998.

[4] M. Iwaki, et al., Proc. of 22nd International Symposium on Space Technology and Science, 2000-c-302000. 